\title{
$\bigcirc$ GIS-BASED MODELLING OF REGIONAL CONSERVATION SIGNIFICANCE
}

\author{
Victor A. Sposito, Department of Primary Industries \\ Correspondence to Victor A. Sposito: Victor.Sposito@dpi.vic.gov.au \\ Elizabeth Morse-McNabb, Department of Primary Industries \\ Correspondence to Elizabeth Morse-McNabb: Elizabeth.Morse-Mcnabb@dpi.vic.gov.au
}

\begin{abstract}
This paper explains an approach for appraising the extent and quality of native vegetation and identifying significant habitats at strategic regional and local levels. The Vegetation and Habitat Conservation Significance Framework (hereafter the framework) is formulated through a planning process which includes seven stages from defining the 'Purpose of the study' (Stage 1) to 'Implementation and monitoring' (Stage 7). The cornerstone of the framework is the formulation, in Stage 3, of a Regional Habitat Significance Mode/ which integrates the Analytic Hierarchy Process (AHP) with Geographic Information System (GIS). An expert workshop (Stage 4) is an integral part of model construction and should comprise 10 to 15 persons including environmental and land use scientists, ecologists, planners and landscape architects with good knowledge of vegetation, biodiversity and habitat matters, as well as relevant decision-makers. Experts are provided with all the data sets generated in Stage 2, and limitations and advantages of each data set are discussed. The initial construction of the model (undertaken at Stage 3 ) is validated, or modified, and then its components are weighted through consensus of the experts. The GIS platform permits the ongoing improvement and input of the latest, relevant information and the preparation of a new assessment in a cyclical planning process. The method is predominantly explained by reference to its application in the rural shire of Macedon Ranges, State of Victoria, Australia.
\end{abstract}

\section{INTRODUCTION}

Protecting high-quality native vegetation is crucial; once it is gone it can not be replaced. Highquality native vegetation contains all the species typical to a particular area with few, if any, weeds, and little, if any, human disturbance. Its protection and enhancement is vital for biodiversity, as it provides habitat for fauna and underpins the functioning of a healthy ecosystem (Crown - State of Victoria 1997; ANZECC 2000).

In this context, this paper explains an approach for assessing the extent and quality of native vegetation and identifying significant habitats at strategic regional and local levels. The Vegetation and Habitat Conservation Significance Framework (hereafter the 'framework'1) is formulated through a cyclical and iterative planning process. The cornerstone of the framework is the development of a Regional Habitat Significance Model which integrates the Analytic Hierarchy Process (AHP) with Geographic Information Systems (GIS).

The assessment of the environmental risk facing vegetation and habitat relies on subjective judgments regarding likelihoods and consequences. There will always be uncertainty associated with the values underpinning judgements because they are the result of expert opinion. Expert knowledge is however considered an important resource that can improve the reliability of modelling (Dzeroski et al. 1997; Venterink and Wassen 1997). It is particularly valuable where no systematic field investigations have been conducted (Maddock and Samways 2000). Radeloff et al. (1999) argue that the incorporation of location-specific knowledge of biologists and other 
experts is a key for enhancing habitat models and thus improving wildlife conservation. In the approach described in this paper, the GIS has been used to achieve this as well as to obtain spatially-explicit vegetation and habitat information from experts. The GIS-based framework provides a virtual environment for experts to gain a rapid insight into the environmental characteristics of the study area, and the information available for its analysis. The advantages of using interactive computer-based tools, such as GIS, for acquiring, storing and analysing expert knowledge are discussed in detail in Wightmann (1995) and Zhu (1999). In a recent project in Lake Eildon National Park, in Victoria, the study focused on eliciting and integrating expert modelling for wildlife habitat modelling (Yamada et al. 2003). It was concluded that a GIS-based approach is important as it provides experts with a spatial context in a repeatable, objective and structured framework. It also simplifies data management and construction of habitat maps.

Decision trees (a sub-set of what is known as logic trees) render decisions into a logical structure that reflects understanding of the system under study. Logic trees are intimately related to expert systems. They are pervasive in many fields, including conservation biology, ecology and species risk assessment, even if sometimes the trees are not drawn (Burgman 2005). There are nevertheless some weaknesses when they are applied to environmental risk analysis. Different experts confronted by the same problem would often formulate different logic trees to represent it. Therefore, different ideas about the logical structure of a problem can contribute to significant differences in estimating risk (Cooke 1991). The AHP, the method deployed to construct the Regional Habitat Significance Model lying at the core of the framework, is based on the construction of a decision tree and, as such, is subject to this criticism. Similarly, differences in data collection and in the interpretation of the data may also influence the construction of the decision tree. In this situation, it is important to subject both the structure of, and the factors included in, the decision tree to sensitivity analyses, by creating the circumstances in which the data generation and tree construction can be independently replicated (Varis 1989; Stoms et al. 1992; Lowell and Jaton 1999).

Moreover, the use of a decision tree for classifying conservation status imposes fuzzy boundaries to the various factors considered in its construction. The choice of the kind and levels of thresholds and logical structure will affect the decisions taken and their consequences. It is argued (Burgman 2005, 239-240) that the best we can do is to accumulate outcomes by monitoring the consequences of decisions, and updating the thresholds and structures iteratively. Revision must take account of the relative frequencies and costs of false-positive and false-negative judgements. Therefore, a complete risk assessment would be distinguished by monitoring outcomes, evaluating the costs and benefits of decisions and revisiting the logic tree tools based on the outcome.

Two widely used methods for assessing the importance of native vegetation are the Habitat Suitability Index and Habitat Hectares model.

The habitat suitability index describes environmental features important for determining species distribution and abundance. This index represents a conceptual model that relates each measurable variable of the environment to the suitability of a site for the species (USFWS 1996; USFWS 1980; Burgman et al. 2001). The indices are scaled from 0 (for unsuitable habitat) to 1 (for optimum conditions). Each environmental variable is represented by a single suitability index, and when the indices are combined a habitat suitability index specific to a particular species is formed. In this model, environmental factors may be assigned weights reflecting the relative im- 
portance of different habitat components. The habitat suitability indices are primarily a process for making a descriptive synthesis of information of the biology and life history of a species' habitat. This is based on a combination of the available data together with expert opinion on the species' biology (Burgman and Lindenmayer 1998). A paper by Yamada et al. (2003) describes the construction of a habitat suitability model for Lake Eildon National Park in the State of Victoria, Australia, using this method.

Victoria's Native Vegetation Management - A Framework for Action (Department of Sustainability and Environment 2002) introduced the concept of the Habitat Hectares method of assessing the quality of a stand of native vegetation. The method combines site-condition and landscape-context components for an assessment. The condition of the remnant vegetation is compared to a high-quality benchmark condition. Site-condition components include: (a) retention of old trees (woodland and forests); (b) retention of the tree canopy cover (woodlands and forest); (c) retention of the cover of, and diversity within, understorey life forms; (d) absence of weed species; and (e) ground litter and the presence of rocks (woodlands and forest). Landscape context includes the size of the remnant vegetation patch and links to, and amount of, neighbouring vegetation patches. Upon completion of the vegetation assessment, the habitat quality is multiplied by the area of the remnant for the overall Habitat Hectare score. This determines if clearing of native vegetation should be allowed as well as what appropriate offset/management actions are required by the landholder (Parkes et al. 2003). While supporting the use of this quantitative approach for assessing habitat quality - because it makes the logic behind the assessment transparent and repeatable - McCarthy et al. (2004) offer several suggestions for its improvement.

A common problem with models of this type developed for the assessment of native vegetation is a lack of appropriate and/or sufficient information as well as differences in interpretation to determine which areas to conserve and enhance (Sutter 1993; Akçakaya et al. 1999; IUCN 1994; IUCN 2001; Beer and Ismail-Zadeh 2003). This is usually compounded by a lack of adequate funding for detailed investigations into essential ecosystem components. The framework explained in this paper can be based on currently available information. It can also highlight areas in which to prioritise future environmental investigations at strategic regional and local levels.

\section{METHOD}

The framework was developed by Primary Industries Research Victoria (PIRVic) in collaboration with the Arthur Rylah Institute and the Victorian Department of Sustainability and Environment. It was initially formulated and applied in the City of Wyndham, in Melbourne, State of Victoria, Australia, as part of the preparation of the Wyndham Environmental Planning Atlas (DPI 2004a). The framework was further developed and applied in the Shire of Macedon Ranges, in Regional Victoria, Australia (DPI 2004b), a substantially different environment from Wyndham. Map 1 shows the location of the State of Victoria in Australia, and both Macedon Ranges and Melbourne. The map also shows the Catchment Management Authority (CMA) regions which have extensive responsibilities for natural resource management, including biodiversity and water resources. This paper explains the method, mostly in light of its application in Macedon Ranges.

The framework is formulated from the standpoint of Ecologically Sustainable Development (ESD) as a Spatial Decision Support System (SDSS) in a Geographic Information Systems (GIS) platform. 
For the purpose of this article, the definition derived from the National Strategy for Ecologically Sustainable Development (COAG 1992) is adopted: Development that improves the total quality of life, both now and in the future, in a way that maintains the ecological processes on which life depends. The three core objectives of ESD are:

1. To enhance individual and community well-being by following a path of economic development that safeguards the welfare of future generations (economic field).

2. To provide for equity within and between generations (or intra- and inter-generational equity) (social field).

3. To protect biological diversity and maintain essential ecological process and life-support systems (biophysical field).

The primary focus of the framework is on the third objective. The framework also provides a suitable context for the application of more detailed procedures, such as the Habitat Hectares Method or the Habitat Suitability Index Method, briefly explained in the introduction.

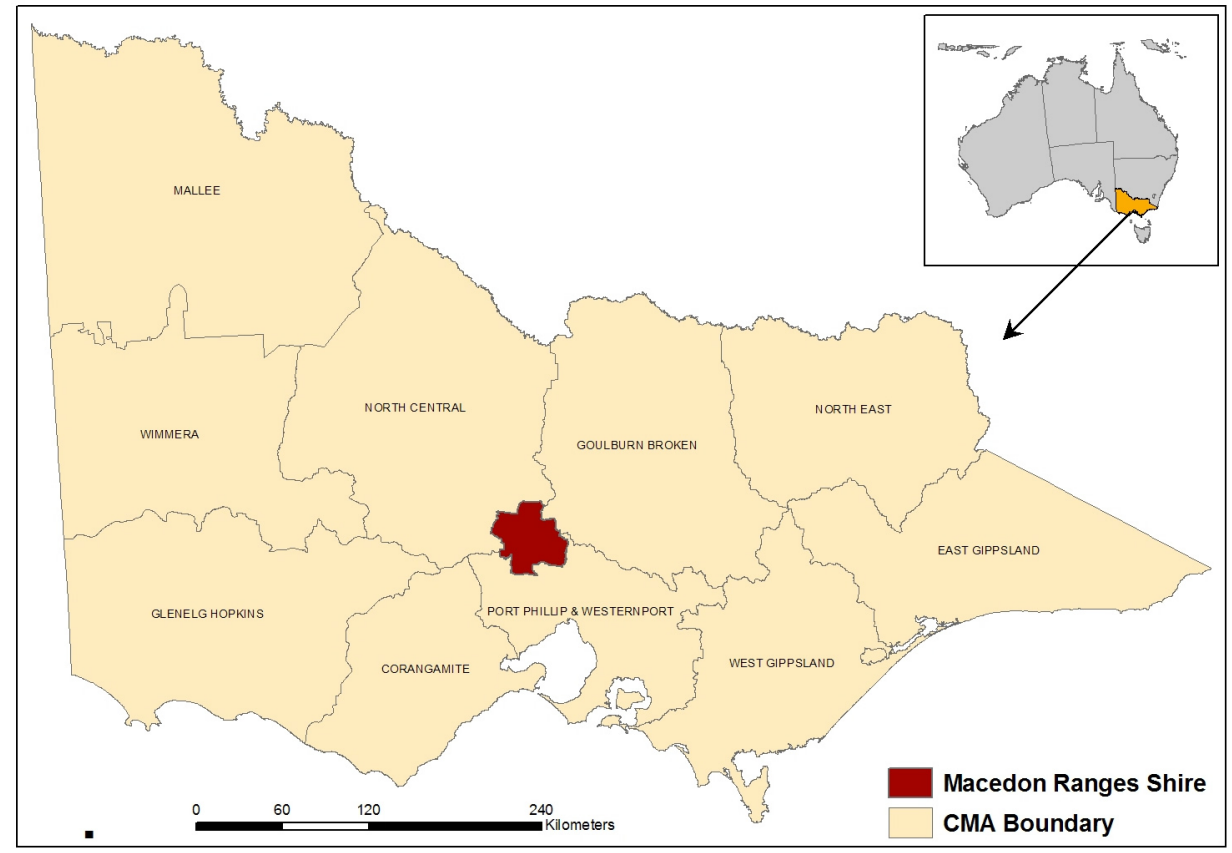

Map 1 Macedon Ranges in the State of Victoria, Australia

\subsection{VEGETATION AND HABITAT CONSERVATION SIGNIFICANCE FRAMEWORK}

\subsubsection{PLANNING PROCESS}

As shown in Figure 1, ${ }^{2}$ the planning process includes seven stages with the tasks, or activities, having been set up as part of a cyclical process. This suits the purpose of exposition because it is desirable to reiterate the activities at various stages in the light of what has been learned and/or as new information becomes available. A brief description of key stages follows. 


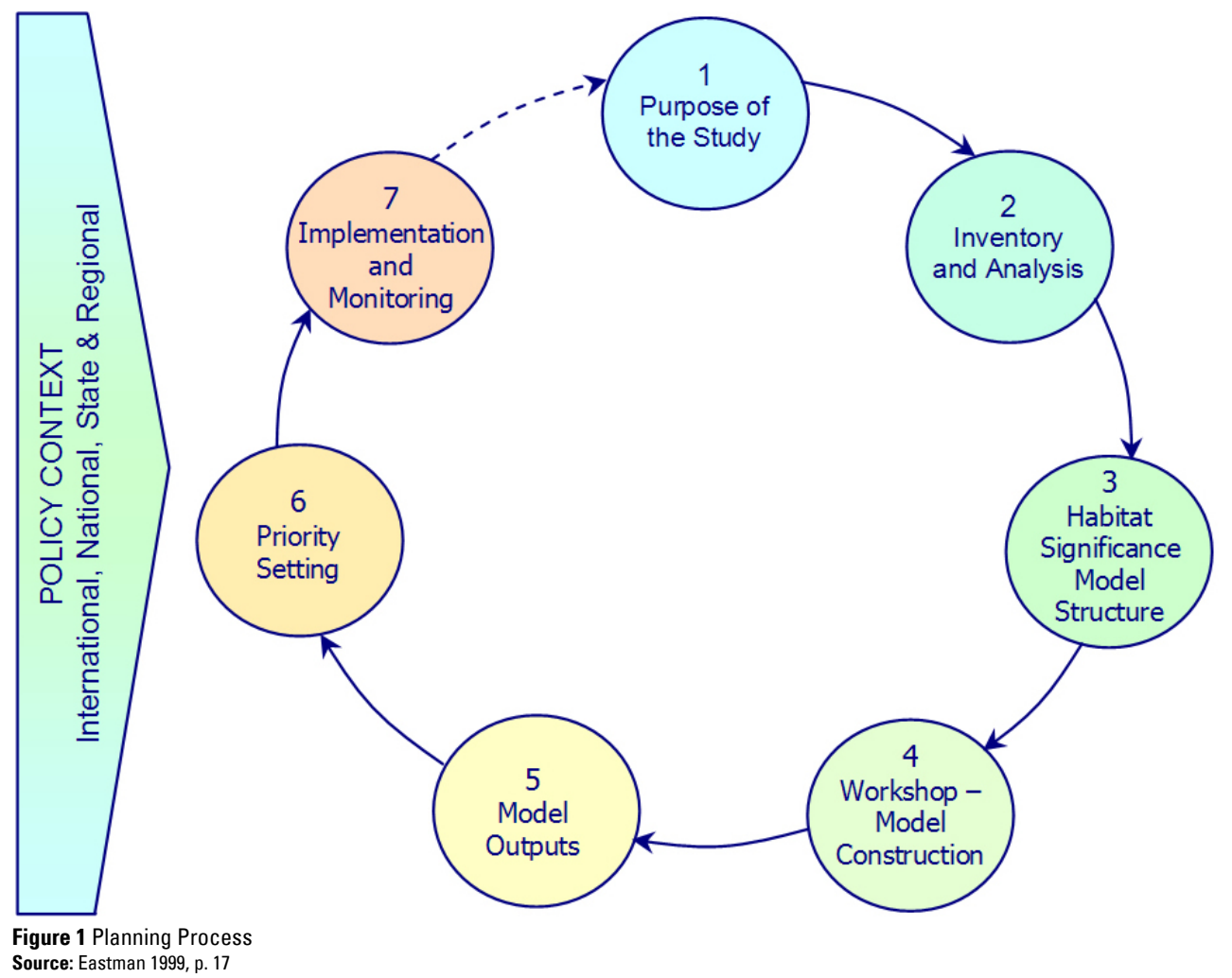

The whole process is informed by the Policy Context, which is depicted in the left of the figure. This includes the relevant international, national and state policy documents. For instance, in the State of Victoria they include: the RAMSAR Convention (1971) for the protection of wetlands of international importance; and the Bilateral Agreements with China - CAMBA (1996) and Japan - JAMBA (1974) for the protection of migratory birds and their environments. The National Strategy for Ecologically Sustainable Development (COAG 1992) and the National Strategy for the Conservation of Australia's Biological Diversity (Commonwealth of Australia 1997) are especially significant because they tie the actions of the Commonwealth and State Governments to pursue ESD, and identify, conserve and manage Australia's biodiversity. At the State Government level, the most important documents are the Flora and Fauna Guarantee Act 1988, the Planning and Environment Act 1987, the Catchment and Land Protection Act 1994, Victoria's Biodiversity Strategy (Crown - State of Victoria 1997), and Victoria's Native Vegetation Management - A Framework for Action (Department of Sustainability and Environment 2002). The latter focuses on native vegetation management and addresses the strategic issues of protection, enhancement and revegetation across the State. The two main concepts outlined in this framework are the goal of Net Gain and the importance not only of native vegetation quantity but also quality. Gain is to be achieved by ensuring the overall losses of native vegetation are less than the overall gains, as well as restricting individual losses of native vegetation whenever possible. The Habitat Hectares method, briefly described in Section 1, is deployed to determine Net Gain. 


\subsubsection{PURPOSE OF THE STUDY - STAGE 1}

The aim of the study ought to be clearly stated from the outset of the planning process - this corresponds to Stage 1 in Figure 1. Macedon Ranges is located in Regional Victoria between Melbourne and the Regional Centre of Bendigo, about $70 \mathrm{~km}$ from Melbourne's CBD. It is predominantly rural in character with some established urban and town/village centres such Romsey, Kyneton, Woodend and Gisborne. It is part of the extensive peri-urban region surrounding the built-up areas of Melbourne. Its population was 37,672 in 2001; it is now growing by more than 1,000 people per year, and is forecast to be about 55,000 by 2031 . In the case of the Macedon Ranges, the study objectives were the following:

1. To improve the information and knowledge on the environmental characteristics of Macedon Ranges, particularly in relation to the vegetation extent, type and quality.

2. To formulate a Vegetation and Habitat Assessment Framework as a Spatial Decision Support System (SDSS) that is easily transferable to Council's GIS platform.

3. To appraise the habitat value of the study area so as to provide guidance in the establishment of priorities for conservation and further investigation by the Macedon Ranges Shire Council.

\subsubsection{INVENTORY AND ANALYSIS - STAGE 2}

Stage 2 of the planning process focuses on the biological assets considered a priority for conservation, like native vegetation, rare and threatened flora and fauna, inland waters (wetlands and rivers) and biosites; and features that provide information on the existing land uses. At this stage, it is critical to uncover all relevant environmental studies and make every attempt to develop this information to a level that can be incorporated in the final model. This process often highlights information gaps. It may be necessary to fill these gaps prior to developing the model if they are critical, or they may be an obvious first step in Stage 6 - Priority Setting. The key information is recorded in map and tabular forms, as components of the SDSD. A concise description of the main components follows.

\section{NATIVE VEGETATION - ECOLOGICAL VEGETATION CLASSES}

Australian native vegetation includes all plant species indigenous to a locality, not introduced species. Land clearing for agriculture and forestry plantations and urbanisation has dramatically reduced both the quality and quantity of native vegetation in Victoria.

Ecological Vegetation Classes (EVCs) are the basic units used for mapping biodiversity and conservation assessment at landscape, catchment and broader scales in Victoria. They are based on the types of plant communities (including species and structural information), ecological information relevant to the species that comprise the communities (including life-form and reproduction), and information about variations in the physical environment (including climate, geology and soils, aspect, elevation, landform and salinity). Each EVC represents one or more plant (floristic) communities that occur in similar types of environments and respond to environmental events, such as bushfires, in similar ways. The conservation status of the EVCs is established in each Australian bioregion, ranging from depleted to least concern (Crown - State of Victoria 1997). A description of the EVCs in Victoria can be seen in a report by the Commonwealth of Australia and Victoria RFA Steering Committee (2000). 
Map 2 shows the ecological vegetation classes of Macedon Ranges, whilst Map 3 depicts its conservation status.

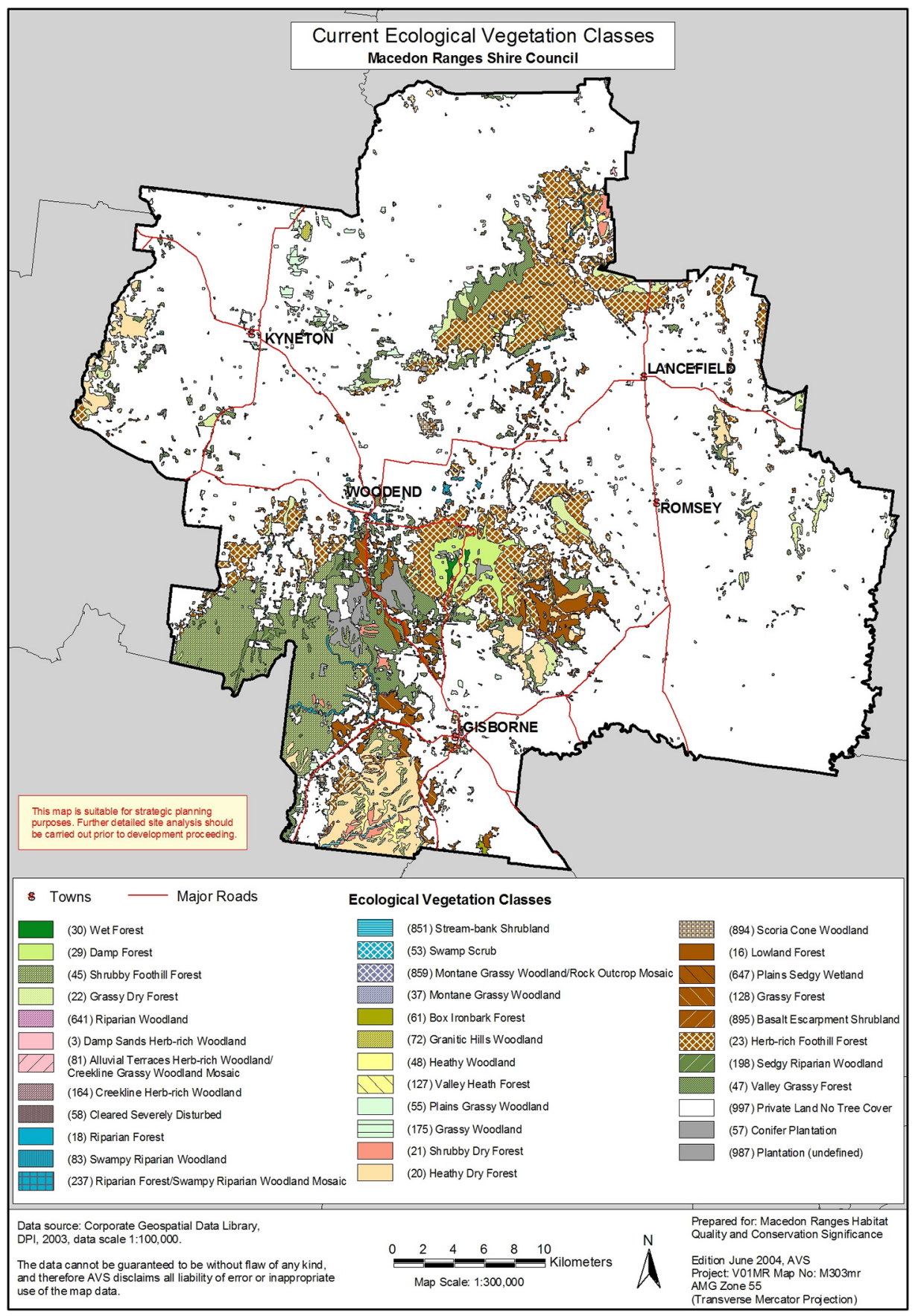

Map 2 Current Ecological Vegetation Classes, Macedon Ranges Shire Council 


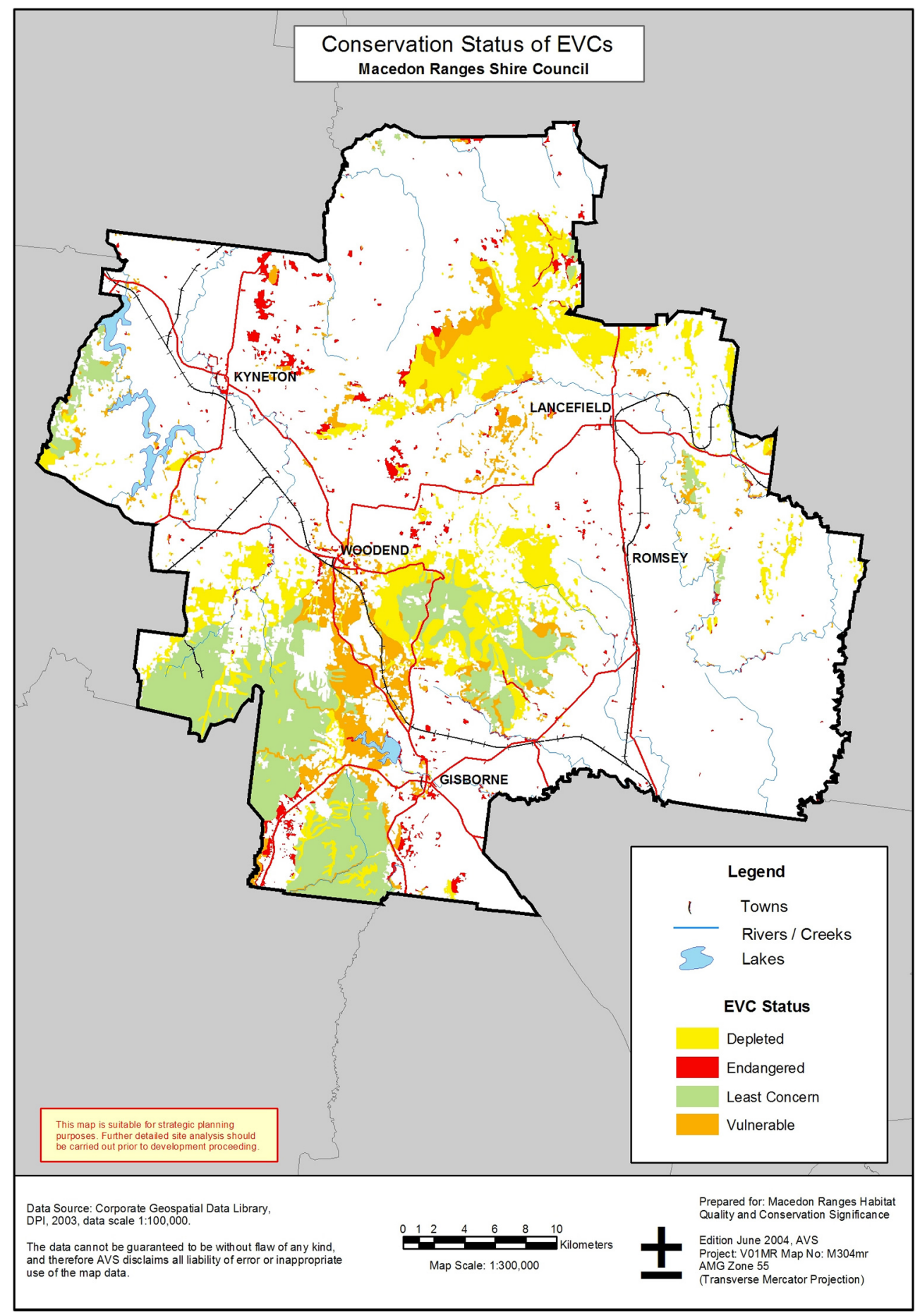

Map 3 Conservation Status of Ecological Vegetation Classes, Macedon Ranges Shire Council 


\section{RARE OR THREATENED FAUNA AND SPECIES}

A $\operatorname{taxon}^{3}$ must meet the criteria established at either national or state level to qualify in a rare or threatened category. The Environment Protection and Biodiversity Conservation Act 1999 is a major consolidation of national biodiversity legislation. Chapter 5, Part 13 - Species and Communities (Division 1 of the Act), sets up the criteria for listing threatened or rare fauna species (AROTS), and preparation of maps indicating their location across the various Australian bioregions is ongoing.

In Victoria, the Flora and Fauna Guarantee Act 1988 provides for the listing of taxa (genera, species, subspecies and varieties) and ecological communities and of flora and fauna. Under the Act, Action Statements provide background information about the species (including description, distribution and habitat) and threats.

\section{WETLANDS AND RIVERS}

Australia's history of subsidence and uplift, volcanic activity, erosion and deposition have produced a rich variety of inland and estuarine aquatic environments, each with its own thriving plants and animal habitats. Wetlands are areas of land that flood naturally on a permanent, seasonal or intermittent basis such as marshes, ponds, lakes, billabongs, meadows and swamps. Australia's wide variety of wetlands offers many unique and valuable habitats to birds, fish, amphibious and other aquatic species (SOEAC 1996, 7-26).

Waterways comprise several elements including the waterway or watercourse (the river or stream itself), riparian land as well as escarpments and surrounding land. Riparian land extends from the river or stream to the edge of the 'wetted zone' to include the stream bank, regularly flooded gullies, wetlands and billabongs located in the floodplain, often defined as the area subject to 1:100 year flood. Maps of rivers, wetlands and flooded areas are generally available in most Australian regions. Map 4 shows the waterways of Macedon Ranges.

\section{LAND USE - AUSTRALIAN LAND USE AND MANAGEMENT (ALUM) CLASSIFICATION}

Land uses have a major impact on Australia's natural resources and environment through their effects on water, soils, nutrients, plants and animals.

Land-use mapping in Australia is based on the system and logic of the ALUM Classification which has a three-level hierarchical structure - primary, secondary and tertiary - broadly organised in terms of the potential degree of modification and impact on a natural state. The following six groupings are used: (1) Conservation and natural environments, (2) Production from relatively natural environments, (3) Production from dryland agriculture and plantations, (4) Production from irrigated agriculture and plantations, (5) Intensive uses, and (6) Water (Bureau of Rural Sciences 2002).

The maps are developed from various data sources highlighting relatively stable land uses like property boundaries, local government area plans and public land management layers. However, because much land use is dynamic and is constantly changing over time. It requires data updates made possible through the use of aerial photography and satellite imagery.

The Bureau of Rural Sciences (www.affa.gov.au/brs), in association with the National Land and Water Resources Audit (www.nlwra.gov.au) and the Australian states, is undertaking a 


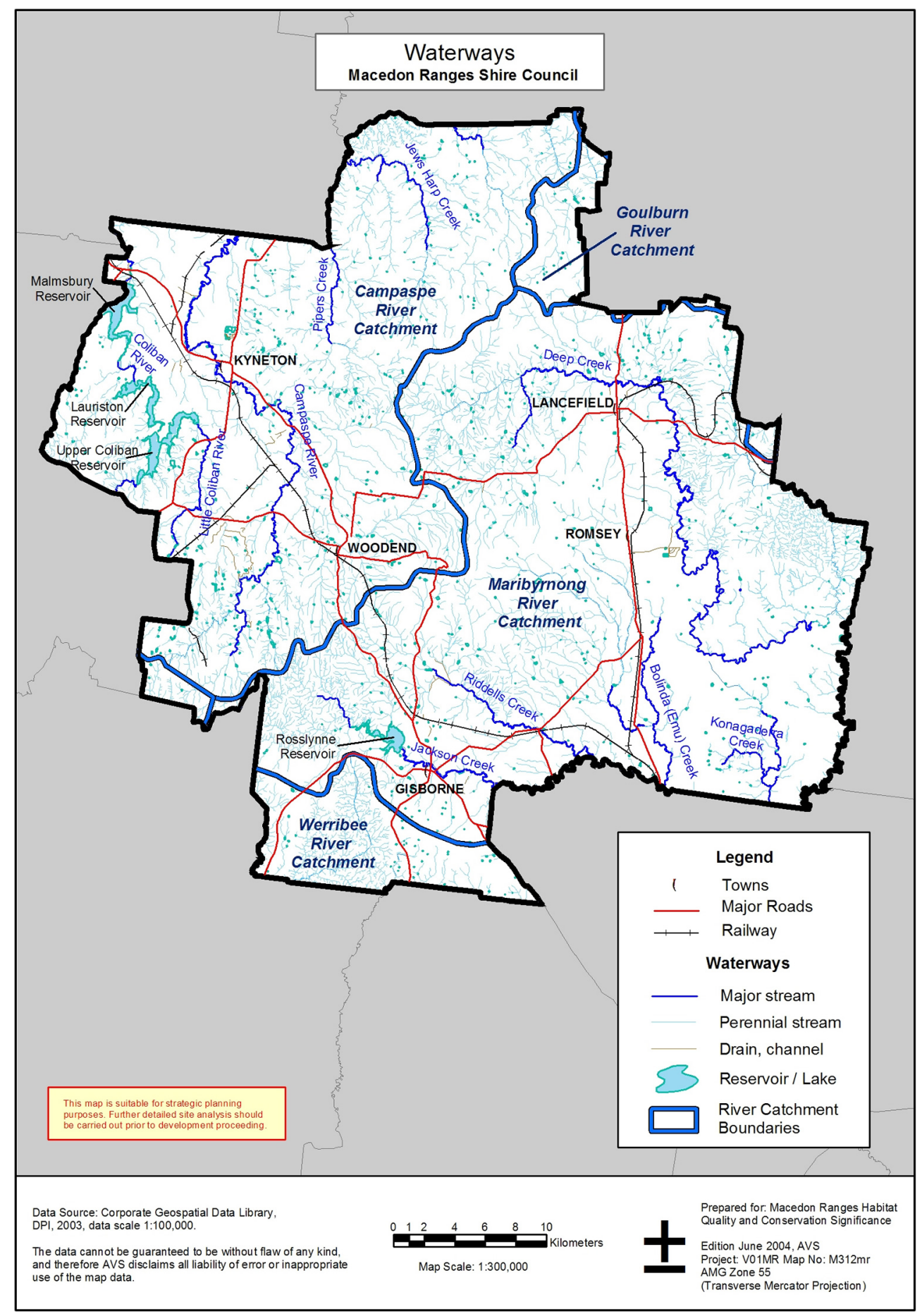

Map 4 Waterways, Macedon Ranges Shire Council 


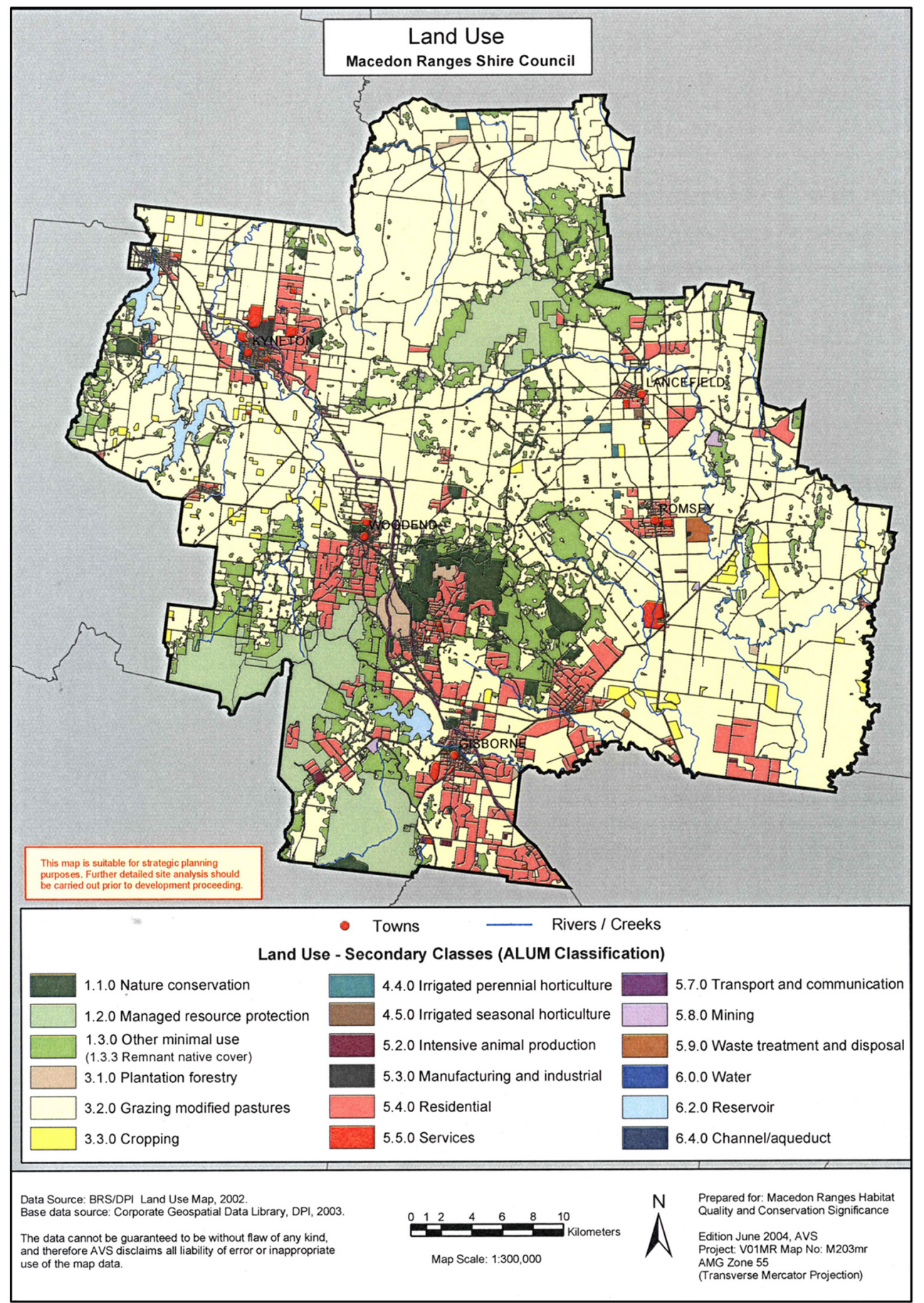

Map 5 Land Use, Macedon Ranges Shire Council 
major program to map land use across the whole continent, at geographic scales ranging from 1:25,000 to 1:250,000, using the ALUM Classification. Each State develops the land use maps using their own base data sets and methods, however, all final land use products must conform to a standard product as determined by the Bureau of Rural Science (BRS).

Map 5 shows the application of the ALUM Classification in Macedon Ranges; where land use is presented at the secondary level of the ALUM Classification hierarchy. There are three classification levels in the ALUM classification. The primary level has only six categories and should only be used for continent scale mapping. The secondary level is the most appropriate for regional mapping as the tertiary level provides information at the commodity level, which at a regional scale is difficult to depict and often inaccurate. Although the BRS only require land use to be mapped at the secondary level, if accurate tertiary information is available it should be included.

\subsubsection{REGIONAL HABITAT SIGNIFICANCE MODEL - STRUCTURE/INITIAL CONSTRUCTION - STAGE 3}

The cornerstone of the framework is the formulation of a Regional Habitat Significance Model, (Stage 3 in the planning process). The model is built through the integration of a Multiple Criteria Evaluation (MCE) method with a GIS, which permits to exploit the full potential of both approaches as evaluation and spatial decision-making tools (Carver 1991; Jankowski 1995).

The MCE method deployed is the Analytic Hierarchy Process (AHP) which ranks factors in order of importance (Saaty 1995 and 2000; Wedley 1990). The combination of AHP and GIS thus improves the reliability of spatial mapping because not all factors (or layers of information) have equal value in determining the significance of vegetation and habitat across a region. The layers can be weighted accordingly. The procedure to carry out AHP is the same for all situations, although certain steps can be given special emphasis. This is fully described in the article by Hossain, Sposito and Evans in this special issue of Applied GIS.

The AHP application to design the Regional Habitat Significance Model deploys the IDRISI GIS computer software developed by Clark University (USA). The linking of the AHP decisionmaking framework to a GIS platform requires interfacing the IDRISI GIS software with the ArcView Model Builder software. The resultant (composite) map is obtained from processing all the map overlays, by reclassifying field values to AHP rankings, multiplying each by the associated weight, and afterwards combining the maps together for each level of the hierarchy.

The initial phase in the formulation of the Regional Habitat Significance Model is the construction of the hierarchy (decision-tree) which incorporates the following aspects (Figure 2):

- The hierarchy (decision tree) comprises categories, components and data.

- Categories are the main groups of features included in the model; they are biological assets, waterways and land use.

- Components are the individual features included in the model, such as native vegetation (EVCs), fauna and flora species' locations, waterways, biosites, etc.

- Data are listed under each component.

Categories and components in the model are then weighted through consensus of an expert panel in the next stage of the planning process. 


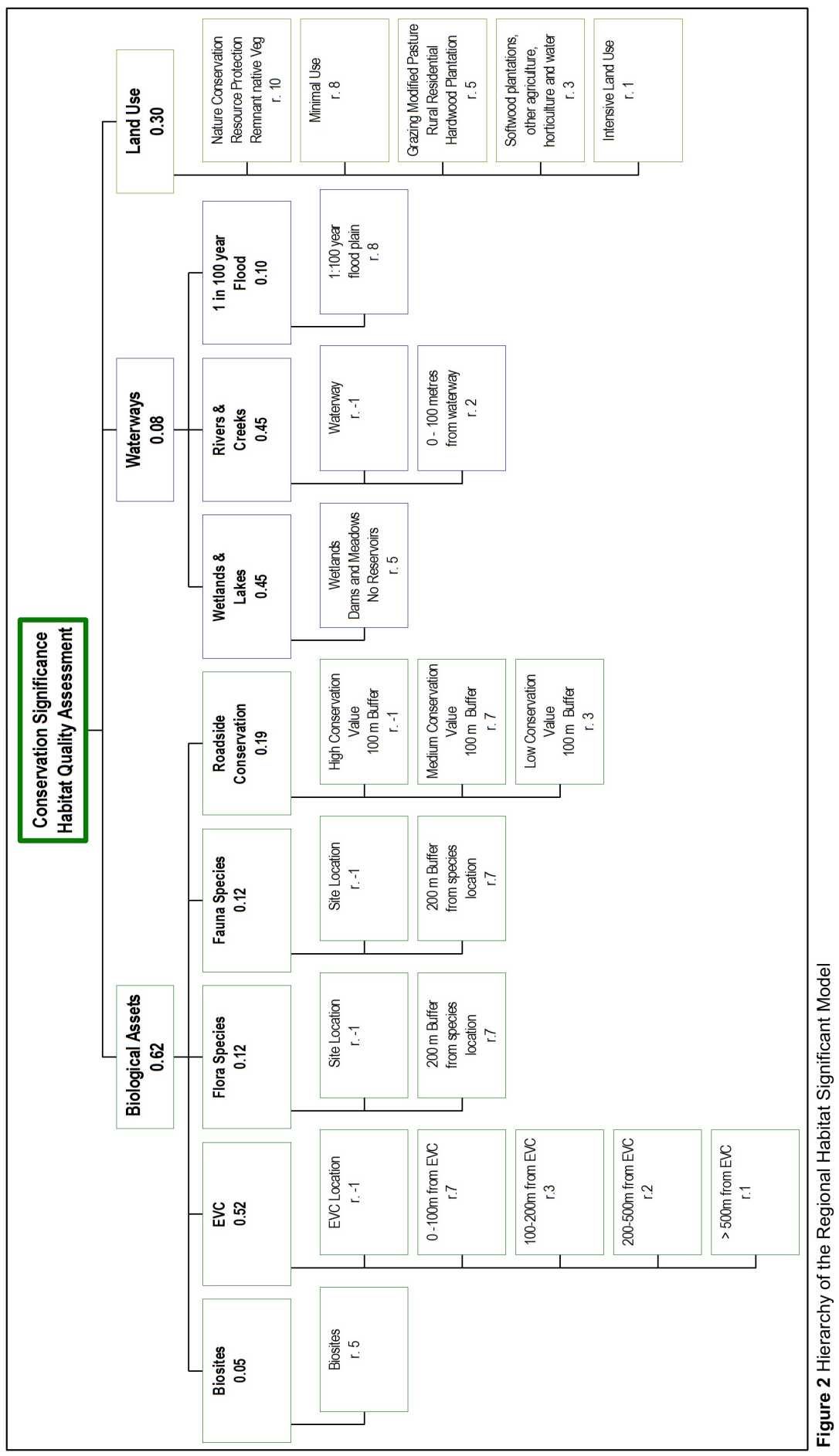




\subsubsection{EXPERT WORKSHOP - FINAL MODEL CONSTRUCTION - STAGE 4}

An expert workshop is an integral part of model construction and should include 10 to 15 people including environmental and land use scientists, ecologists, planners and landscape architects who have good knowledge of vegetation, biodiversity and habitat matters, as well as relevant decision-makers with knowledge of the study area.

Experts were provided with all the data sets generated in Stage 2, Inventory and Analysis, of the planning process. Limitations and advantages/disadvantages of each data set were thoroughly discussed. The initial construction of the model (undertaken in Stage 3) was validated or modified, and then categories and components were weighted through the consensus of the experts.

- Weightings give an indication of the influence that a category has on the overall significance of the study area.

- Weightings are given on a numerical scale (0 to 1 ), with the lowest value (0) having no influence, and the highest value (1) having a total influence on the area's habitat significance.

- Data are rated on a scale of -1 to 10 because it is the same scale utilised by ArcView Model Builder (see above). A score of -1 indicates a very significant feature, such as remnant EVC, which must be preserved. Scores of 0-10 provide an indication of the significance of each feature in terms of habitat, with 10 being highly significant and 0 being of only slight significance (most experts are unwilling to suggest that an area has no significance).

Figure 2 shows the hierarchy developed for the Habitat Significant Model for the Macedon Ranges. Biological assets were considered most important in this case because of the quality of the information in this category, and the type of environment found in the Macedon Ranges area. Each area would have different weighting based on the accuracy of the data and type of ecosystem. However, in most cases the land use category would have significant impact on the model (thus having a high weighting) because current land use practice will influence the environmental outcomes possible at each site.

\section{RESULTS}

\subsection{MODEL OUTPUTS AND VALIDATION - STAGE 5}

The system developed by PIRVic creates maps and data tables for every calculation in the model, allowing users to investigate areas individually for more information, and it can also be easily adjusted for new data or different weightings.

Map 6 shows the main output of the model for the Macedon Ranges. Four categories of habitat are displayed, ranging from very highly significant habitat to land requiring further investigation. The moderately significant habitat generally surrounding areas of very high significance also has some habitat value and can act as a buffer against surrounding, threatening land uses.

The validation of the resulting map was undertaken in a complementary workshop with the same group of experts who participated in the construction of the model for the study area. Because of its computerised nature, the new model output could be run in real time during the workshop, and therefore modified as required. 


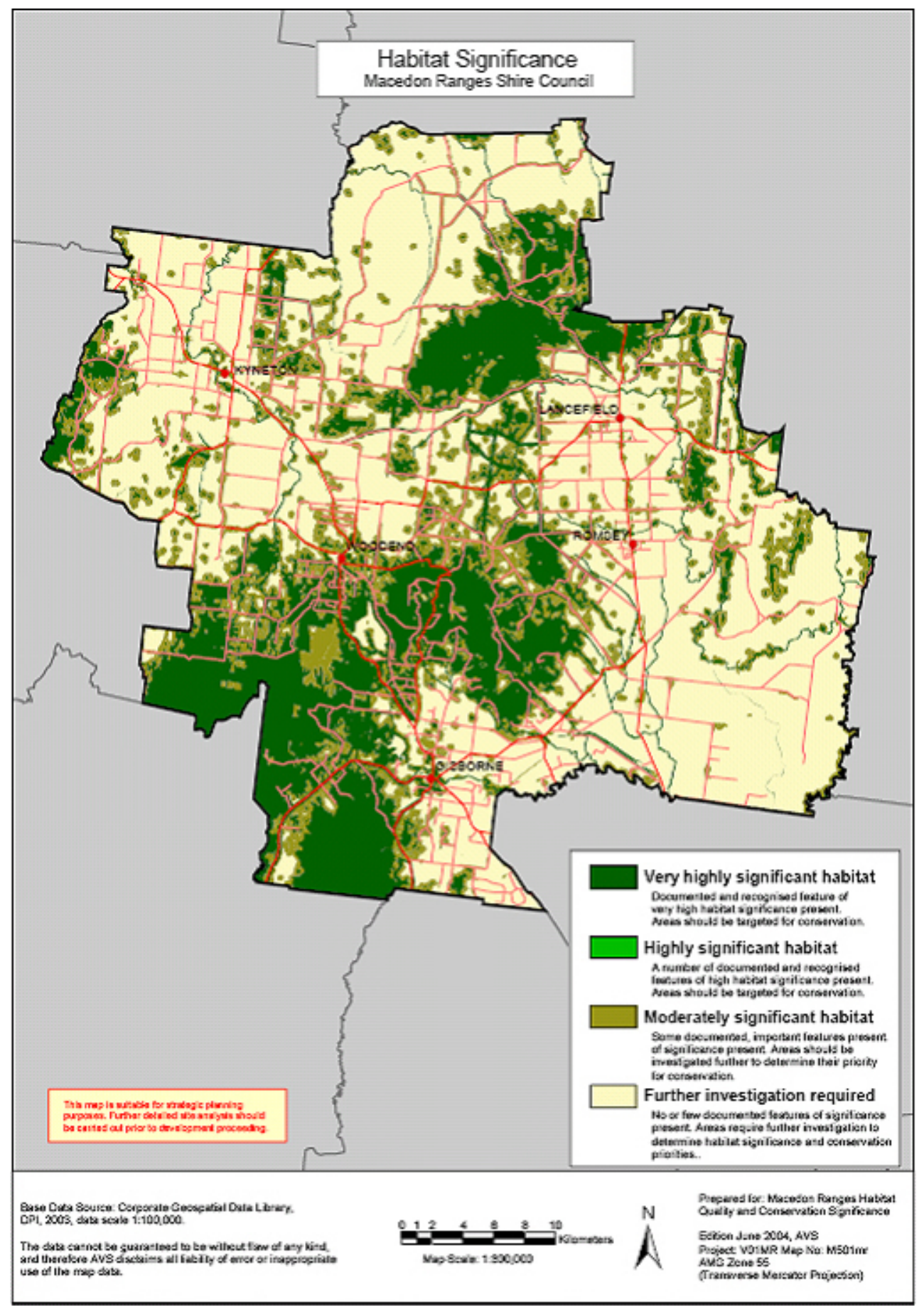

Map 6 Habitat Significance, Macedon Ranges Shire Council 


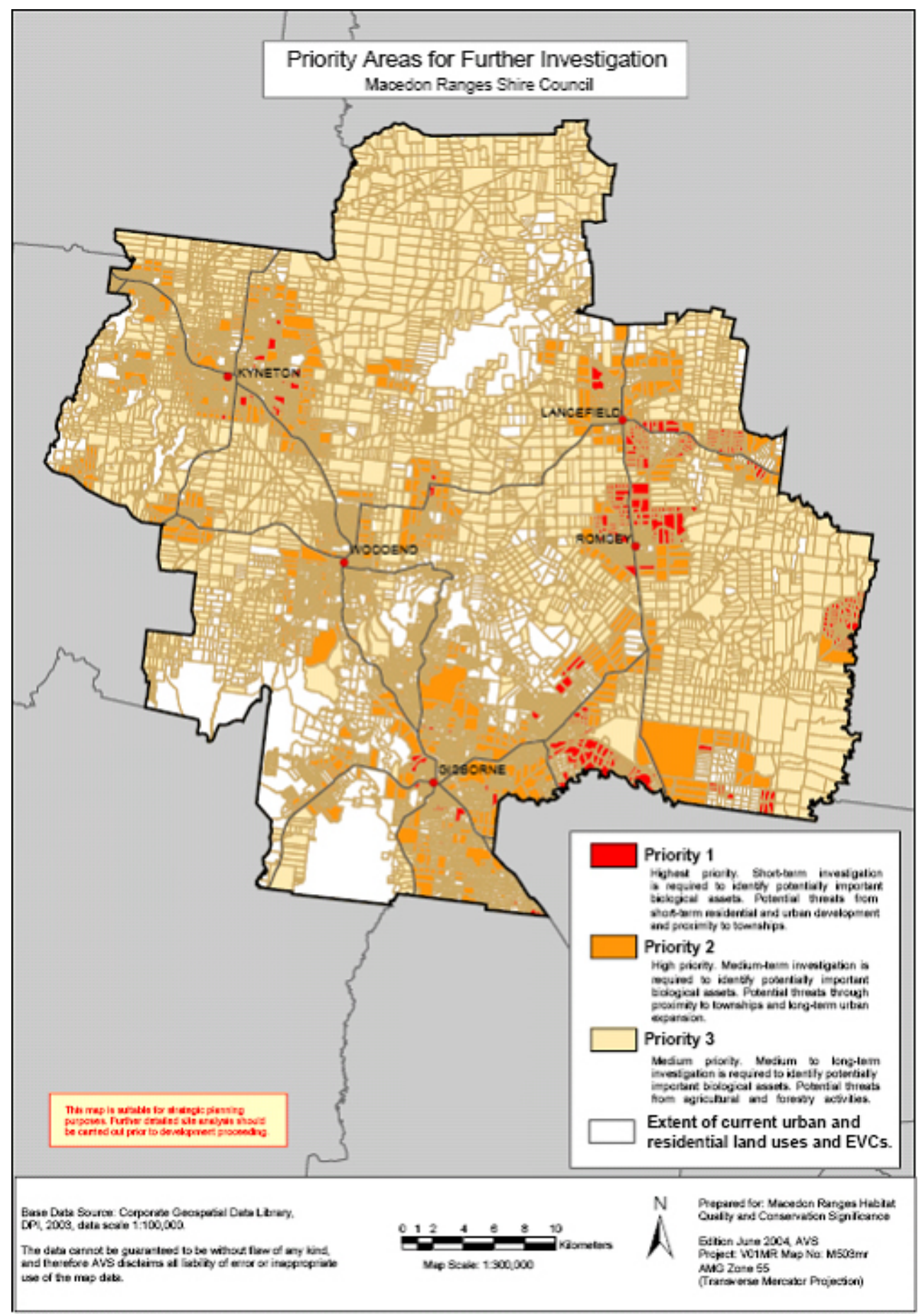

Map 7 Priority Areas for Further Investigation, Macedon Ranges Shire Council 


\subsection{PRIORITY AREAS AND IMPLEMENTATION - STAGES 6 AND 7}

As would happen in most cases, there are extensive areas in the Macedon Ranges where no appropriate data exists. Because of the high costs required for detailed mapping of vegetation and habitats, the investigation of those areas needs to be prioritised and a program for sequentially undertaking the investigations in forthcoming years must be established. This is Stage 6 in the planning process, as depicted in Figure 1. Map 7 displays the priorities agreed for the Macedon Ranges. The map concentrates on areas outside existing known biological assets and highlights those areas with (potential) habitat significance, or biological assets under threat from urban development, proximity to townships, and agricultural and forestry activities.

Macedon Ranges Shire can now have the ability to understand the scale of the information gaps and set in place methods to acquire relevant information. They can begin to implement a process for measuring and monitoring the environmental aspects of the priority areas identified by the model, as shown in Map 7.

\section{CONCLUSION AND SUMMARY}

The construction of the framework as a SDSS allows monitoring the consequences of decisions, the ongoing improvement of the relevant information and the preparation of a new assessment in a never-ending, cyclical planning process. Given the strategic intent of the framework, it must be supported by field investigations at a site level. Through priority setting, the framework also establishes an appropriate context for the application of more detailed environmental planning methods; for example, the Habitat Hectares or the Habitat Suitability Index method described in Section 1.

The greatest conflict between physical/economic development and biodiversity conservation is now taking place in all the peri-urban regions of Australia, especially around its metropolises, where ESD principles must guide development. Methods that render operational the principles of ESD should underpin the planning and design of all new developments and therefore be extensively applied by spatial planners, landscape planners, architects and environmental engineers.

\section{ACKNOWLEDGEMENTS}

The PIRVic Project Teams that, under the direction of the co-author of this note, Victor Sposito, developed the methodology described in this paper included: Elizabeth Morse-McNabb, Stephen Gyaw, Hemayet Hossain, Kathryn Sheffield and Dale Watson. Graeme Newell led the Arthur Rylah Institute group; and the Macedon Ranges Shire Council representatives were Ian Morris, CEO, Margaret Brennan and Jonathan Lachlan. The comments of three anonymous reviewers resulted in considerable improvement being made to this paper.

Funding for the research, and for the studies first applying the methodology, was provided by the Victorian Department of Primary Industries, the Macedon Ranges Shire Council and the City of Wyndham, in Victoria, Australia. 


\section{ENDNOTES}

Framework in this article refers to a combination of: (i) an approach that prescribes an entire process of assessment and which may include (ii) a certain method or methods (sequences of actions designed to achieve a specific result), which may in turn employ various (iii) tools or instruments or means by which a specific task is accomplished.

The planning process depicted in Figure 1 is an applied version of the generic model of the rational decision-making process. This should not be confused with the framework for assessing quality/extent of native vegetation and habitat significance, which is built through the planning process.

The word 'species' has two distinct meanings. As a biological species concept, species is defined as group of organisms that breeds internally but is reproductively isolated from other groups. The second meaning is just one of the end points along the base of the taxonomic pyramid, the ultimate unit of classification of a group of organisms regardless of whether or not they are capable of mating with other organisms. That is, species is a taxon, a unit of classification (Atkins 2003, 10).

\section{REFERENCES}

Akçakaya, H.; Ferson, S.; Root, W. 1999. RAMAS Red List: Threatened Species Classification under Uncertainty. Version 2, Applied Biomathematics. Setauker, New York.

ANZECC. 2000. National Framework for the Management and Monitoring of Australia's Native Vegetation.

Canberra, Australia: Australia and New Zealand Environment Conservation Council, Environment.

Atkins, P. 2003. Galileo's Finger - The Ten Great Ideas of Science, Oxford: Oxford University Press.

Beer, T.; Ismail-Zadeh, A. (eds). 2003. Risk Science and Sustainability. Kluwer: Dordrecht.

Bureau of Rural Sciences - BRS. 2002. Land Use Mapping at Catchment Scale - Principles, Procedures and

Definitions, $2^{\text {nd }}$ edition. Canberra: Commonwealth Department of Agriculture, Fisheries and Forestry

- DEST.

Burgman, M. 2005. Risks and Decisions for Conservation and Environmental Management. Cambridge:

Cambridge University Press.

Burgman, M.; Lindenmayer, D. 1998. 'Identifying Habitat'. In Conservation Biology for the Australian

Environment, Chipping Norton, NSW: Surrey Beatty \& Sons. pp. 229-244.

Burgman, M; Breininger, D; Duncan, B; Ferson, S. 2001. 'Setting reliability bounds on habitat suitability indices'. Ecology Applied 11 (1): 70-78.

Carver, S. 1991. 'Integrating multi-criteria evaluation with geographical information systems'. Journal of

Geographical Information Systems 5 (3): 321-339.

Commonwealth of Australian Governments - COAG. 1992. National Strategy for Ecologically Sustainable Development, Canberra: DEST.

Commonwealth of Australia. 1997. The National Strategy for the Conservation of Australia's Biological Diversity, Canberra: DEST.

Commonwealth of Australia and Victoria Regional Forestry Agreement (RFA) Steering Committee. 2000. Biodiversity Assessment, Melbourne: DNRE.

Cooke, R., 1991. Experts in Uncertainty: Opinion and Subjective Probability in Science. Oxford University Press. Oxford.

Crown - State of Victoria, Department of Natural Resources and Environment - DNRE. 1997. Victoria's Biodiversity Strategy, 3 vols. Melbourne: DNRE.

Department of Natural Resources and Environment - DNRE. 2002. Biodiversity Action Planning, Melbourne: DNRE.

Department of Primary Industries - DPI. 2004a. Wyndham Environmental Planning Atlas, Melbourne: DPI. Department of Primary Industries - DPI. 2004b. Macedon Ranges - Habitat Quality and Conservation Significance, Melbourne: DPI. 
Department of Sustainability and Environment - DSE. 2002. Victoria's Native Vegetation Management - A Framework for Action, Melbourne: DSE.

Douglas, G. 1982. 'Geology'. In Atlas of Victoria, edited by Duncan, J. Melbourne: VGPO. pp. 11-16.

Dzeroski, S; Grboviae, J; Walley, W; Kompare, B. 1997. 'Using machine learning techniques in the construction of models, II, Data Analysis with rule induction'. Ecological Modelling 95: 95-111.

Eastman, R. 1999. 'Multicriteria Evaluation and GIS'. In Geographic Information System edited by Longley, P.; Goodchild, M.; Magure, D. and Rhind, W. New York: John Wiley \& Sons.

Hossain, H; Sposito, V; Evans, C. 2006. 'Sustainable land resource assessment in regional and urban systems'. Applied GIS 2 (3): 24.1-24.21. DOI: 10.2104/ag060024.

IUCN. 1994. IUCN Red List of Threatened Animals. International Union for the Conservation of Nature. Gland. Switzerland: IUCN.

IUCN. 2001. IUCN Red List Categories. IUCN Species Survival Commission. Gland, Switzerland: The World Conservation Union.

Jankowski, P. 1995. 'Integrating geographical information systems and multiple criteria decision-making'. International Journal of Geographical Information Systems 9 (3): 251-273.

Lowell, K.; Jaton, A. 1999. (eds), Spatial Accuracy Assessment: Land Information Uncertainty in Natural Resources, Chelsea: Sleeping Bear Press.

Maddock, A; Samways, M. 2000. 'Planning for biodiversity conservation based on the knowledge of biologists'. Biodiversity Conservation 9 (8): 1153-1169.

McCarthy, M; Parris, K; van der Ree, R; McDonnell, M; Burgman, M; Williams, N; McLean, N; Harper, M; Meyer, R; Hahs, A; Coates, T. 2004. 'The habitat hectares approach to vegetation assessment: An evaluation and suggestions for improvement'. Ecological Management and Restoration 5 (1): 24-27. DOI: 10.1111/j.1442-8903.2004.00173.x.

Parkes, D; Newell, G; Cheal, D. 2003. 'Assessing the quality of native vegetation: The habitat hectares approach'. Ecological Management and Restoration 4S: S29-S38.

Radeloff, V; Pidgeon, A; Hostert, P. 1999. 'Habitat and population modelling of roe deer using an interactive geographic information system'. Ecological Modelling 114: 287-304.

Robb, C; Peterman, R. 1998. 'Application of Bayesian decision analysis to management of sockeye salmon (Oncorhynchus nerka) fishery'. Canadian Journal of Fisheries and Aquatic Sciences 55: 86-98.

Saaty, T. 1995. Decision Making for World Leaders: The Analytic Hierarchy Process for Making Decisions in a Complex World, Pittsburgh: RWS Publications.

Saaty, T. 2000. Fundamentals of Decision Making and Priority Theory with the Analytic Hierarchy Process, Pittsburgh: RWS Publications.

State of the Environment Advisory Council - SOEAC. 1996. Australia: State of the Environment, Melbourne: CSIRO Publishing.

Stoms, D; Davis, F; Cogan, C. 1992. 'Sensitivity of wildlife models to uncertainties in GIS data, Photogram. Eng'. Remote Sensing 58 (6): 843-850.

Sutter, G., 1993. Ecological Risk Assessment. Boca Raton, Florida: Lewis.

USFWS. 1980. Habitat Evaluation Procedures Report ESM 102, Washington DC: United States Fish and Wildlife Services.

USFWS. 1996. Habitat Evaluation Procedures Report 870 FW1, Washington DC: Unites States Fish and Wildlife Service.

Varis, O. 1989. 'The analysis of preferences in complex environmental judgements: A focus in the Analytic Hierarchy Process'. Journal of Environmental Management 38: 283-294.

Venterink, H; Wassen, M. 1997. 'A comparison of six models predicting vegeration response to hydrological habitat change'. Ecological Modelling 101: 347-361. 
Wedley, W. 1990. 'Combining qualitative and quantitative factors: an analytic hierarchy approach'. Socio-Economic Planning Sciences 24: 57-64.

Wightmann, R. 1995. 'GIS-based forest management planning in New Brunswick'. Proceedings of Ninth Annual Symposium of Geographic Information Systems in Natural Resources Management. Vancouver, BC, GIS World 2: 503-506.

Yamada, K; Elith, J; McCarthy, M; Zerger, A. 2003. 'Eliciting and integrating expert knowledge for wildlife habitat modelling'. Ecological Modelling 165: 251-264.

Zhu, A. 1999. 'A personal construct-based knowledge acquisition process for natural resource mapping'. International Journal of Geographic Information Systems 13 (2): 119-141.

Cite this article as: Sposito; Victor. Morse-McNabb, Elizabeth. 2006. 'GIS-based modelling of regional conservation significance'. Applied GIS 2 (3): pp. 20.1-20.20. DOI: 10.2104/ag060020. 